\title{
Capsule Commentary on Unroe et al., Hospice Use Among Nursing Home and Non-Nursing Home Patients
}

\author{
Susan E. Merel, MD \\ Division of General Internal Medicine, University of Washington Medical Center, Seattle, WA, USA.
}

$\mathrm{J}$ Gen Intern Med 30(2):240

DOI: $10.1007 / \mathrm{s} 11606-014-3103-7$

(c) Society of General Internal Medicine 2014

A recent Institute of Medicine report called for a major redesign of end-of-life care in the United States, avoiding acute care services unlikely to benefit patients and using the cost savings for services not covered by insurers. ${ }^{1}$

We know that nursing home residents with advanced dementia often suffer from pain and dyspnea and commonly undergo burdensome interventions in the last three months of life, ${ }^{2,3}$ and that there is a correlation between these transitions and other markers of suboptimal end-of-life care. ${ }^{3}$ On the other hand, nursing home residents receiving hospice care are more likely to receive guideline-based pain treatment and have advance directives, and are less likely to have feeding tubes and physical restraints. ${ }^{4}$

Spurred by rule changes proposed by the Centers for Medicare and Medicaid Services (CMS) that would reduce payments for hospice patients residing in nursing homes, Unroe and colleagues have completed a study that informs the debate over how to best deliver end-of-life care in a manner that is both patient-centered and cost-effective. ${ }^{5}$

The authors analyzed Medicare, Medicaid and Minimum Data Set data for almost 4,000 hospice patients from one health system. Half of the patients were in non-nursing home hospice, while one-third used hospice in nursing homes. Nursing home hospice patients were older and more likely to have dementia. Overall, $30 \%$ of hospice patients stayed less than one week, and a "near transitions" group receiving hospice care within 30 days of a nursing home stay was more likely to have a short hospice stay. Hospice patients moving in and out of nursing homes and the "near transitions" group had higher Medicare costs. The identification of this "near transitions" group is notable - this is a group that is incurring higher costs, may be receiving services that are not improving quality of life, and would benefit from comprehensive palliative care beginning earlier in their illness. An increase in funding for palliative care services would also benefit the large number of patients with late hospice referrals. Reducing reimbursement for nursing home hospice patients may result in later enrollment in hospice, potentially increasing costs. These proposed rule changes may have unexpected consequences and merit further study.

Conflict of Interest: The author has no conflict with any of the material in this manuscript.

Corresponding Author: Susan E. Merel, MD; Division of General Internal MedicineUniversity of Washington Medical Center, Seattle, WA 98195, USA (e-mail: smerel@uw.edu).

\section{REFERENCES}

1. IOM(Institute of Medicine). Dying in America: improving quality and honoring individual preferences near the end of life. Washington, DC: The National Academies Press; 2014.

2. Mitchell SL, Teno JM, Kiely DK, et al. The clinical course of advanced dementia. N Engl J Med. 2009;361:1529-1538.

3. Gozalo P, Teno JM, Mitchell SL, et al. End-of-life transitions among nursing home residents with cognitive issues. New Engl J Med. 2011;365:1212-1221.

4. Stevenson DG, Bramson JS. Hospice care in the nursing home setting: a review of the literature. J Pain Symptom Manag. 2009;38:440-451

5. Unroe KT, Sachs GA, Dennis ME, et al. Hospice use among nursing home and non-nursing home patients. J Gen Intern Med. 2014. doi:10.1007/ s11606-014-3080-x.

Published online December 2, 2014 